\title{
Availability of family planning services and quality of counseling by faith-based organizations: a three country comparative analysis
}

Janine Barden-O'Fallon ${ }^{1,2}$

\begin{abstract}
Background: Faith-based organizations (FBOs) have a long history of providing health services in developing countries and are important contributors to healthcare systems. Support for the wellbeing of women, children, and families is evidenced through active participation in the field of family planning (FP). However, there is little quantitative evidence on the availability or quality of FP services by FBOs.

Methods: The descriptive analysis uses facility-level data collected through recent Service Provision Assessments in Malawi (2013-14), Kenya (2010), and Haiti (2012) to examine 11 indicators of FP service and method availability and nine indicators of comprehensive and quality counseling. The indicators include measures of FP service provision, method mix, method stock, the provision of accurate information, and the discussion of reproductive intentions, client's questions/concerns, prevention of sexually transmitted infections, and return visits, among others. Pearson's Chi-square test is used to assess the selected indicators by managing authority (FBO, public, and other private sector) to determine statistical equivalence.

Results: Results show that FBOs are less likely to offer FP services than other managing authorities $(p<0.05)$. For example, $69 \%$ of FBOs in Kenya offer FP services compared to $97 \%$ of public facilities and $83 \%$ of other private facilities. Offering long-acting or permanent methods in faith-based facilities is especially low (43\% in Malawi, 29\% in Kenya and 39\% in Haiti). There were few statistically significant differences between the managing authorities in comprehensive and quality counseling indicators. Interestingly, Haitian FBOs often perform as well or better than public sector health facilities on counseling indicators, such as discussion of a return visit (79\% of FBO providers vs. $68 \%$ of public sector providers) and discussion of client concerns/questions (52\% vs. 49\%, respectively).
\end{abstract}

Conclusions: Results from this analysis indicate that there is room for improvement in the availability of FP services by FBOs in these countries. Quality of counseling should be improved by all managing authorities in the three countries, as indicated by low overall coverage for practices such as ensuring confidentiality (22\% in Malawi, $47 \%$ in Kenya and $12 \%$ in Haiti), discussion of sexually transmitted infections (18\%, $25 \%, 17 \%$, respectively), and providing services to youth (53\%, 27\%, 32\%, respectively).

Keywords: Family planning, Faith-based organizations, Malawi, Kenya, Haiti

\footnotetext{
Correspondence: bardenof@email.unc.edu

${ }^{1}$ Carolina Population Center, University of North Carolina at Chapel Hill,

Chapel Hill, NC, USA

${ }^{2}$ Department of Maternal \& Child Health, Gillings School of Global Public

Health, University of North Carolina at Chapel Hill, 400 Meadowmont Village

Circle, 3rd Floor, Chapel Hill, NC 27517, USA
}

(c) The Author(s). 2017 Open Access This article is distributed under the terms of the Creative Commons Attribution 4.0 International License (http://creativecommons.org/licenses/by/4.0/), which permits unrestricted use, distribution, and reproduction in any medium, provided you give appropriate credit to the original author(s) and the source, provide a link to the Creative Commons license, and indicate if changes were made. The Creative Commons Public Domain Dedication waiver (http://creativecommons.org/publicdomain/zero/1.0/) applies to the data made available in this article, unless otherwise stated. 


\section{Plain English summary}

Faith-based organizations (FBOs) have a long history of providing health services in developing countries and are important contributors to healthcare systems. Support for the wellbeing of women, children, and families is evidenced through active participation in the field of family planning (FP). However, there is little evidence on the availability or quality of FP services by FBOs. The objective of this research is to investigate the provision of FP services by FBOs in Malawi, Kenya, and Haiti. Data collected from health facilities is used to examine 11 measures of FP service and method availability and nine measures of FP counseling quality according to the managing authority- faith-based, public, or other private sector provider. Findings show that faith-based facilities are less likely to offer FP services than facilities of other managing authorities. Offering or providing long-acting or permanent methods in faith-based facilities is especially low. There were few significant differences in comprehensive and quality counseling between the managing authorities. Interestingly, Haitian faith-based facilities often perform as well or better than public sector health facilities on assessed measures. This analysis contributes information on a topic which has very little evidence. Results from this analysis indicate that there is room for improvement in the availability of FP services by FBOs in these countries. Quality of counseling should be improved by all managing authorities in the three countries.

\section{Background}

Faith-based organizations (FBOs) have a long history of providing health services in developing countries and are important contributors to healthcare systems. With a mission to serve their communities, especially the poor and other marginalized groups, FBOs are particularly well-positioned to contribute to health care delivery. In many countries, FBOs supplement government health services, contribute resources such as buildings, equipment, and staff from a wide range of donors, and are well-integrated in the communities they serve [1]. However, the actual degree to which FBOs contribute to healthcare has not been adequately quantified. In a first attempt to measure religious contributions to health systems, the African Religious Health Assets Program estimated approximately $40 \%$ of national health services in Lesotho and 30\% in Zambia were provided by religious entities [2]. An average of "about $40 \%$ in many subSaharan African nations" was then reported in a seminal World Health Organization report [1] and has since been widely cited as the estimated contribution of FBOs in healthcare services $[3,4]$. A more recent attempt to clarify and quantify the contribution of FBOs to healthcare delivery in developing countries found wide variation, ranging from 4 to $44 \%$ for the assessed health care indicators [5].
The study's authors acknowledge that a large gap remains in knowledge and data on this issue [5]. A review of research on faith-based health care in Africa published in 2015 echoes this finding [6]. Furthermore, there is a scarcity of evidence on the quality of healthcare services by FBOs as compared to those found in the public or other private sector [6]. One exception is a systematic review of literature from six African countries, which found that maternal and newborn services provided by FBOs were similar to those offered by the public sector, while client reported satisfaction and quality were better [7].

FBOs have an inherent interest in improving the wellbeing of the women, children, and families for whom they serve and are active in the field of family planning (FP) and reproductive health. Faith entities support various elements of FP as essential for reducing maternal and child morbidity and mortality, eradicating poverty, and minimizing or eliminating induced abortion; education and other social welfare programs are also understood to benefit from support of FP [8]. FP is accepted by many Christian and Muslim organizations and leaders [9]: over 1,000 religious leaders have endorsed a commitment to safe, affordable, accessible and comprehensive FP services [10]. With a high level of credibility and trust within their communities, FBOs influence reproductive health choices and behavior, and have the standing to influence decisions on FP at all levels, from the individual to the policy level [11].

Despite such broad support for family health and FP in particular, there are noteworthy areas in which FBOs and secular health services can differ. For example, there may be religious-based objections to the provision of certain FP services or contraceptive methods. This would be the case for organizations supported by the Catholic Church, for example, which officially supports only natural FP methods such as the Standard Days Method, TwoDay Method, and Lactational Amenorrhea Method. FBOs may also object to offering FP services to certain types of clients, such as unmarried adolescents, whose sexual behavior would be forbidden by religious teachings. Indeed, religious barriers against modern contraception are cited as reasons for individual non-use of contraception. For example, among Kenyan women not intending to use contraception in the future, $9 \%$ report a religious prohibition as their reason for future non-use [12]. A study from Pakistan reported 22\% of respondents were not using contraception due to religious concerns [13].

The availability and accessibility of FP services and an array of contraceptive methods are key elements of global FP policies. The global FP initiative started in 2012, FP2020, has a goal of providing 120 million women and girls with modern contraceptives by 2020 [14]. To help achieve this goal, the FP2020 Rights and Empowerment Working Group has established common principles for each of ten dimensions of FP [14]. Availability and service 
quality are two of the ten dimensions [14]. Regarding availability, the principles state that health care facilities, providers and contraceptive methods need to be available "to ensure that individuals can exercise full choice from a full range of methods" and that furthermore, contraceptive methods are to be accessible without informational or other barriers [14]. Regarding service quality issues, the principles state that "client-provider interactions respect informed choice, privacy and confidentiality, client preferences, and needs" [14]. A core partner of FP2020 is the United States Agency for International Development (USAID), which is also the world's largest FP bilateral donor [15]. USAID-supported FP programs are guided by principles of volunteerism and informed choice, meaning that programs are required to provide information on a wide variety of FP choices, including the benefits and health risks of particular methods, and that a wide variety of methods are offered [16]. The Livingston Amendment ensures that FBOs providing natural FP methods are supported as long as they offer information about or access to other methods through referral [16].

Currently, there is insufficient information on the degree to which faith-based facilities support method availability, volunteerism and free choice on a range of methods, and how FBOs compare to other FP providers on these issues [17]. The objective of this research is to investigate the provision of FP services by FBOs in three countries, Malawi, Kenya, and Haiti. These three countries were chosen for analysis based on the availability of recent health facility data and the active participation of FBOs in the healthcare sector. Specifically, the research will examine the availability of FP services and methods and the quality of counseling in FBOs as compared to public and other private sectors in the three selected countries.

\section{Methods}

This is a descriptive analysis conducted for three countries with recent Service Provision Assessments (SPA), carried out by the Demographic and Health Survey program, and includes Malawi, Kenya, and Haiti [18-20]. The SPA use four data collection tools, including a facility inventory questionnaire, health provider interviews, provider-client observations, and exit interviews with clients to collect comprehensive data on a number of key health service indicators, including availability, readiness, quality, and client satisfaction. SPA data are publically available and cover a variety of key health services in addition to FP, such as child health, maternal and newborn health, HIV/ AIDS, and malaria. Written consent for interviews and oral permission to observe consults were obtained at the time of survey administration. Survey protocols were reviewed by the ICF International IRB and in-country
IRBs and comply with the U.S. Department of Health and Human Services regulations for the protection of human subjects. Malawi, Kenya and Haiti were selected based on the availability of recent SPA data and sufficient representation of FBOs in the data.

The Malawi SPA was conducted in 2013-14. The data are from a census of facilities; of a total of 1,060 facilities, 977 (92\%) completed all data collection tools and are included in the dataset. The Kenya SPA was conducted in 2010 and provides a nationally representative sample of the country's health facilities, including all national and provincial hospitals, which covers approximately $11 \%$ of the total population of the country's health facilities. Hospitals, maternity and stand-alone voluntary, counseling and testing facilities were oversampled; sampling was not conducted on the basis of managing authority. The Haiti SPA was conducted in 2012. Like Malawi, it is a census of facilities with 905 of 907 total facilities included in the dataset. Further details on SPA data and data collection can be found at http://dhsprogram.com/What-WeDo/Survey-Types/SPA.cfm [21].

For this analysis, all facilities were classified by their managing authority as either 1) faith-based; 2) public sector; or 3) other private sector (includes private forprofit and private not-for-profit). Eleven indicators for FP service and method availability were selected, and include:

1. Percent of facilities offering any FP services

2. Percent of facilities offering at least 2 modern methods

3. Percent of facilities offering at least 4 modern methods

4. Percent of facilities offering any long acting or permanent method: intrauterine contraceptive device (IUCD), implant, female sterilization, or male sterilization

5. Percent of facilities providing any FP services

6. Percent of facilities providing at least 2 modern methods

7. Percent of facilities providing at least 4 modern methods

8. Percent of facilities providing any long acting or permanent method: IUCD, implant, female sterilization, or male sterilization

9. Number of days per week facility offers FP services (categorized 1-2, 3-4, 5+)

10. Percent of facilities with method provided available on day of assessment for combined oral contraception pills ("pills"), progesteroneonly injectable, IUCD, and all provided methods. At least one method must be observed and valid for use to qualify.

11. Percent of facilities with routine user fees or charges/routine fees for FP services 
The indicators for availability reflect those presented in the SPA reports, covering the areas of method mix and specific methods offered, frequency of services, and stock availability [18-20]. An indicator on fees for services was added to reflect an additional potential barrier to services. In the SPA surveys, "a facility is said to offer a FP method if the facility reports that it provides the method, prescribes the method for clients to obtain elsewhere, or counsels clients on the method without actually making that method available to the client in the facility. A facility is said to provide a family planning method if the facility reports that it stocks the method and makes it available to clients when they visit the facility. In other words, these clients can obtain the method without leaving the facility" ([18], p.66). Though this terminology can be somewhat pedantic, it provides useful information on whether facilities are offering a full range of methods even when they are not delivering them, due to facility size, lack of appropriately trained providers, or other reasons. Abortion is not included as a FP service in the SPA.

Nine quality of counseling indicators were chosen using the Quick Investigation of Quality (QIQ), a validated tool designed to assess the quality of family planning services [22]. Of the 25 recommended indicators in the QIQ, those that were specifically related to provider's interpersonal skills, provision of information, and client's method choice, and that were included in the SPA data, were selected for analysis. An additional indicator for services to youth was added.

1. Percent of providers who looked at and wrote on client's health card

2. Percent of providers who used any visual aids

3. Percent of providers who discussed a return visit

4. Percent of providers assuring client of confidentiality

5. Percent of providers asking clients about reproductive intentions. Indicator includes providers asking clients about the desire for a(nother) child and/or the desired timing for birth of the next child.

6. Percent of providers discussing questions/concerns with client on current method. Indicator includes if provider asked client if he/she had questions or concerns regarding current method, or if client expressed concerns about method or asked questions about method, including the possible side effects of method.

7. Percent of providers discussing client's perceived risk of sexually transmitted infections (STI/HIV), use of condoms to prevent STI/HIV, or dual method use

8. Percent of providers giving accurate information on the method accepted. Indicator is a composite of three items: provider explains how to use method, discusses possible side effects, and what to do if side effects.
9. FP provider provides services to youth (FP provider offers "youth friendly" or services to adolescents). Services to adolescents or youth friendly services are defined as services "designed to be youth friendly with the specific aim of encouraging youth or adolescent utilization."

The indicators focus on availability of services and comprehensive quality of counseling and do not measure other aspects of service provision, such as technical competence (i.e. training or supervision) or facility readiness (i.e. supplies or infection control). Data for the availability indicators come from the facility audit, while counseling indicators use data from observations, client exit interviews, and provider interviews. Pearson's Chisquare test was used to assess the frequency of the selected indicators across each type of managing authority (FBO, public sector, and other private sector) to determine statistical equivalence. Results of the multiple category comparisons that are statistically significant at $p<0.05$ are indicated in the tables. Analyses are weighted for sample design (Kenya) and non-response (Malawi; Haiti) to compensate for any over- or underrepresentation of facility type in the data, and use weights provided in each dataset. Sample sizes are not weighted in order to present actual numbers used in the final samples.

\section{Settings \\ Malawi}

The Christian Health Association of Malawi is a health service network of independent church-affiliated facilities, located mostly in rural areas [18]. The Association is co-owned by the Malawi Council of Churches and the Episcopal Conference of Malawi; about half of its facilities are Catholic and half Protestant. The Christian Health Association of Malawi facilities provide the vast majority of faith-based service provision in Malawi and are a key element of the healthcare system.

Malawi is a mostly Christian country, though Muslims make up a considerable portion of the population: $21 \%$ of Malawians report being Catholic, 65\% as other Christian, and $13 \%$ as Muslim [23]. Generally, Muslims tend to have higher fertility rates than non-Muslims, and this is the case in Malawi: Muslims have a total fertility rate of 7.0 as compared to 5.3 for Catholics, and 5.6 for other Christians [23]. Contraceptive use also tends to be lower for Muslims (32\%) than for non-Muslims (48\%) [23]. Overall, 42\% of married women age 15-49 are current modern contraceptive users, with the most widely used methods being injectables (26\%) and female sterilization (10\%) [24]. Among current modern method users, 9\% of women in Malawi report receiving their method at a facility managed by the Christian Health Association of Malawi, compared 
to $74 \%$ of women receiving a method from a public facility, and $17 \%$ from other private facilities [24].

\section{Kenya}

Three main faith networks provide health services in Kenya. The Kenya Conference of Catholic Bishops is the largest faith-based health network and the umbrella organization for all Catholic hospitals and clinics. The network only provides natural FP methods. The secondlargest faith-based health network is the Christian Health Association of Kenya, which is the umbrella organization for all Protestant hospitals and clinics. The Supreme Council of Kenya Muslims is also an active network in health service provision.

Religious affiliations in Kenya are similar to those in Malawi: $22 \%$ are Catholic, $68 \%$ are other Christian, and 7\% are Muslim [23]. Fertility is higher for Muslims than non-Muslims (a total fertility rate of 5.1 compared to 4.5) and contraceptive use is lower (20\% compared to $48 \%$ ) [23]. Modern contraceptive use in Kenya is the highest among the three countries in this study, at 53\% among currently married women age 15-49 [12]. The most common methods are injectables (26\%) and implants (10\%) [12]. Only about $2 \%$ of women report getting their method at a faith-based church, mission hospital or clinic, as compared to $60 \%$ from the public sector, $31 \%$ from other private, and 6\% from "other" sources [12].

\section{Haiti}

There is no uniting health care network operating in Haiti, though many religious organizations are involved in health service delivery, including for example, IMA World Health, Catholic Medical Mission Board, and International Child Care. Demographic and Health Survey data show that $53 \%$ of women and $45 \%$ of men belong to a Protestant denomination, while $39 \%$ of women and $42 \%$ of men are Catholic; $7 \%$ of women and $12 \%$ of men report having no religion [25].

The modern contraceptive prevalence rate among married women age 15-49 in Haiti is $31 \%$, with injectables
(19\%) and the male condom (5\%) as the most common methods [25]. Unlike Malawi and Kenya, the public sector is not the most common source of contraception: $30 \%$ of women report the private sector as their source of method, followed by the public (23\%), "mixed" (14\%), and non-institutional, non-medical and "other" (34\%) [25]. The source of method by FBO is not reported in the country's Demographic and Health Survey.

\section{Results}

\section{Distribution of facilities by managing authority}

Of the 167 faith-based facilities included in the Malawi SPA, 160 belong to the Christian Health Association of Malawi. All health facilities managed by FBOs in Malawi represent $17 \%$ of the sample, which compares to $48 \%$ by the public sector and $35 \%$ by the other private sector (see Table 1). The majority of faith-based facilities are health centers $(66 \%)$, followed by hospitals $(26 \%)$. This pattern is more similar to public facilities than other private facilities, which are mostly clinics $(87 \%)$.

The Kenya SPA data show that faith organizations manage $13 \%$ of health facilities in Kenya, as compared to the public sector, at $50 \%$, and other private sector, at $37 \%$. In Kenya, the majority of faith-based facilities are dispensaries (63\%), which is also the most common facility type in the public sector (72\%). The other private sector facilities are most likely to be clinics (71\%).

In Haiti, the SPA data indicate that FBOs manage 20\% of health facilities, as compared to $38 \%$ by the public sector and $42 \%$ by all other private sector. The most common faith-based facility type are clinics (42\%), followed by health centers without beds (37\%). Both of these facility types are the most common in the public and other private sector as well.

\section{Availability of services}

Tables 2, 3 and 4 present results for the eleven indicators of availability of services and methods by managing authority. Assessment of the results by country shows that in Malawi (Table 2), there are many statistically

Table 1 Percentage of faith-based, public and other private sector facilities in Malawi, Kenya, Haiti; MSPA 2013-14, KSPA 2010, HSPA 2012

\begin{tabular}{|c|c|c|c|c|c|c|c|c|c|c|c|c|}
\hline & \multicolumn{4}{|l|}{ Malawi } & \multicolumn{4}{|l|}{ Kenya } & \multicolumn{4}{|l|}{ Haiti } \\
\hline & $\begin{array}{l}\text { FBO } \\
(n=167)\end{array}$ & $\begin{array}{l}\text { Public } \\
(n=478)\end{array}$ & $\begin{array}{l}\text { Other Private } \\
(n=332)\end{array}$ & $\begin{array}{l}\text { TOTAL } \\
(n=977)\end{array}$ & $\begin{array}{l}\mathrm{FBO} \\
(n=93)\end{array}$ & $\begin{array}{l}\text { Public } \\
(n=347)\end{array}$ & $\begin{array}{l}\text { Other Private } \\
(n=255)\end{array}$ & $\begin{array}{l}\text { TOTAL } \\
(n=695)\end{array}$ & $\begin{array}{l}\mathrm{FBO} \\
(n=183)\end{array}$ & $\begin{array}{l}\text { Public } \\
(n=342)\end{array}$ & $\begin{array}{l}\text { Other Private } \\
(n=380)\end{array}$ & $\begin{array}{l}\text { TOTAL } \\
(n=905)\end{array}$ \\
\hline \multicolumn{13}{|l|}{ Type of Facility } \\
\hline Hospital & 26 & 10 & 6 & 12 & 9 & 9 & 5 & 7 & 7 & 15 & 15 & 13 \\
\hline $\begin{array}{l}\text { Health } \\
\text { center }\end{array}$ & 66 & 72 & 5 & 48 & 16 & 17 & 3 & 11 & 15 & 14 & 14 & 14 \\
\hline Dispensary & 1 & 9 & 2 & 5 & 63 & 72 & 14 & 49 & NA & NA & NA & NA \\
\hline Clinic & 6 & 4 & 87 & 34 & 10 & 2 & 71 & 29 & 42 & 51 & 28 & 40 \\
\hline Other $^{a}$ & 1 & 5 & 0 & 2 & 2 & 1 & 7 & 3 & 37 & 21 & 42 & 33 \\
\hline
\end{tabular}

NA Not applicable. Column totals of over $100 \%$ are due to rounding

${ }^{\mathrm{a}}$ Malawi = Health post; Kenya = Maternity, Voluntary counseling \& testing centers; Haiti = Health center without beds 
Table 2 Percentage of faith-based, public, and other private sector facilities with family planning services available in Malawi; MSPA 2013-14

\begin{tabular}{|c|c|c|c|c|}
\hline & $\mathrm{FBO}(n=167)$ & Public $(n=478)$ & Other Private $(n=332)$ & TOTAL $(n=977)$ \\
\hline \multicolumn{5}{|l|}{ Availability of Service Indicators } \\
\hline Offers any FP services & 57 & 95 & 77 & $83^{* *}$ \\
\hline Offers at least 2 modern methods & 56 & 95 & 76 & $82^{* *}$ \\
\hline Offers at least 4 modern methods & 54 & 93 & 69 & $78^{* *}$ \\
\hline Offers any of: IUCD, implant, female or male sterilization & 43 & 88 & 55 & $69^{* *}$ \\
\hline Provides any FP services & 57 & 95 & 77 & $82^{* *}$ \\
\hline Provides at least 2 modern methods & 56 & 94 & 74 & $81^{* *}$ \\
\hline Provides at least 4 modern methods & 48 & 89 & 59 & $71^{* *}$ \\
\hline Provides any of: IUCD, implant, female or male sterilization & 32 & 78 & 43 & $58^{* *}$ \\
\hline $\begin{array}{l}\text { Facility has routine user fees or charges (Malawi, Haiti); routine } \\
\text { fees for family planning services (Kenya) }\end{array}$ & 98 & 8 & 80 & $48^{* *}$ \\
\hline \# of days per week facility offers FP services & & & & $(n=810)$ \\
\hline $1-2$ days & 35 & 42 & 14 & $32^{* *}$ \\
\hline 3-4 days & 2 & 9 & 1 & $5^{* *}$ \\
\hline $5+$ days & 63 & 49 & 85 & $62^{* *}$ \\
\hline Method stock on day of assessment & & & & ( $n=$ varies by method $)$ \\
\hline Provides pills with pills available & 80 & 90 & 79 & $86^{* *}$ \\
\hline Provides injectable with injectable available & 89 & 90 & 88 & 89 \\
\hline Provides IUCD with IUCD available & 37 & 55 & 80 & $68^{* *}$ \\
\hline Every method provided available & 40 & 41 & 45 & 42 \\
\hline
\end{tabular}

** Significant at $p<0.05$

Table 3 Percentage of faith-based, public, and other private sector facilities with family planning services available in Kenya; KSPA 2010 FBO $(n=93) \quad$ Public $(n=347) \quad$ Other Private $(n=255) \quad$ TOTAL $(n=695)$

Availability of Service Indicators

Offers any FP services

Offers at least 2 modern methods

Offers at least 4 modern methods

Offers any of: IUCD, implant, female or male sterilization

Provides any FP services

Provides at least 2 modern methods

41

Provides at least 4 modern methods

Provides any of: IUCD, implant, female or male sterilization

Facility has routine user fees or charges (Malawi, Haiti); routine fees for family planning services (Kenya)

\# of days per week facility offers FP services

$$
\begin{aligned}
& \text { 1-2 days } \\
& \text { 3-4 days }
\end{aligned}
$$$$
5+\text { days }
$$

Method stock on day of assessment

Provides pills with pills available

Provides injectable with injectable available

Provides IUCD with IUCD available

Every method provided available

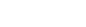

97
9
95
58
9
9
9
38
68

97
96
95
58
96
96
94
38
68
11
0
89

\section{6}

95

58

96

96

94

38

68

58

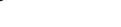

$\begin{array}{ll}83 & 88^{*} \\ 83 & 85^{*} \\ 75 & 81^{*} \\ 51 & 51^{*} \\ 81 & 83^{*} \\ 78 & 82^{*} \\ 64 & 76^{*} \\ 37 & 35 \\ 92 & 76^{*}\end{array}$

$88^{* *}$
$85^{* *}$
$81^{* *}$
$51^{* *}$
$83^{* *}$
$82^{* *}$
$76^{* *}$
35
$76^{* *}$
$(n=573)$
12
0
88

88

( $n=$ varies by method)

94

95

$92^{* *}$

$77^{* *}$ 
Table 4 Percentage of faith-based, public, and other private sector facilities with family planning services available in Haiti; HSPA 2012

\begin{tabular}{|c|c|c|c|c|}
\hline & $\mathrm{FBO}(n=183)$ & Public $(n=342)$ & Other Private $(n=380)$ & TOTAL $(n=905)$ \\
\hline \multicolumn{5}{|l|}{ Availability of Service Indicators } \\
\hline Offers any FP services & 89 & 93 & 72 & $84^{* *}$ \\
\hline Offers at least 2 modern methods & 86 & 93 & 68 & $81^{* *}$ \\
\hline Offers at least 4 modern methods & 79 & 88 & 59 & $74^{* *}$ \\
\hline Offers any of: IUCD, implant, female or male sterilization & 39 & 50 & 29 & $39^{* *}$ \\
\hline Provides any FP services & 82 & 91 & 62 & $77^{* *}$ \\
\hline Provides at least 2 modern methods & 78 & 90 & 56 & $73^{* *}$ \\
\hline Provides at least 4 modern methods & 63 & 70 & 41 & $56^{* *}$ \\
\hline Provides any of: IUCD, implant, female or male sterilization & 21 & 27 & 16 & $21^{* *}$ \\
\hline $\begin{array}{l}\text { Facility has routine user fees or charges (Malawi, Haiti); routine } \\
\text { fees for family planning services (Kenya) }\end{array}$ & 98 & 94 & 92 & $94^{* *}$ \\
\hline \# of days per week facility offers FP services & & & & $(n=753)$ \\
\hline $1-2$ days & 2 & 3 & 6 & $4^{* *}$ \\
\hline 3-4 days & 4 & 1 & 7 & $4^{* *}$ \\
\hline $5+$ days & 94 & 96 & 87 & $92^{* *}$ \\
\hline Method stock on day of assessment & & & & ( $n=$ varies by method $)$ \\
\hline Provides pills with pills available & 88 & 90 & 85 & 88 \\
\hline Provides injectable with injectable available & 90 & 89 & 89 & 89 \\
\hline Provides IUCD with IUCD available & 25 & 56 & 64 & 55 \\
\hline Every method provided available & 62 & 61 & 55 & 59 \\
\hline
\end{tabular}

** Significant at $p<0.05$

significant differences in the availability of FP services and methods by managing authority. $57 \%$ of faith-based facilities offer FP services, compared to $95 \%$ of public and $77 \%$ of other private facilities $(p<0.05)$. Most facilities offering FP services offer at least four modern methods. Overall, 69\% of all facilities in Malawi offer a long acting method, such as an IUCD, implant, or female or male sterilization, with $43 \%$ of faith-based facilities offering such methods $(p<0.05)$. However, the provision of long acting methods (i.e. providing the methods on-site) is lower on average, at $58 \%$, and $32 \%$ for faith-based facilities $(p<0.05)$. Faith-based facilities have a routine user fee in $98 \%$ of facilities; this is also a common practice in other private facilities $(80 \%)$, but not in the public sector $(8 \%)(p<0.05)$. Almost twothirds of faith-based facilities are open five or more days/week, which is less than other private facilities (85\%) but compares favorably to the public sector (49\%) $(p<0.05)$. Finally, having valid stock of popular methods such as pills and injectables is relatively common for all facilities, but less so for the IUCD (68\% overall, $37 \%$ in faith-based facilities) $(p<0.05)$. Having all methods provided in stock on the day of the interview occurred for $42 \%$ of all facilities, with no statistical difference by managing authority.

Results for Kenya (Table 3) show that $69 \%$ of faith-based facilities offer FP services, as compared to $97 \%$ of public and $83 \%$ of other private sector facilities $(p<0.05)$. The availability of methods shows a large difference by managing authority in Kenya: $44 \%$ of faith-based, $95 \%$ of public, and $75 \%$ of other private facilities offer at least four modern methods; this drops for offering any long acting method: only $29 \%$ of faith-based facilities offer such methods, as compared to $58 \%$ of public and $51 \%$ of other private facilities $(p<0.05)$. Provision of long acting methods is low for all types of managing authority (35\%). Routine user fees are less common in faith-based facilities $(58 \%)$ than in the public (68\%) or other private $(92 \%)$ sector $(p<0.05)$. Most facilities in Kenya that offer FP services are open five or more days a week $(88 \%)$ and have stock on hand for pills (94\%) and injectables (95\%). Faithbased facilities are almost as likely to have all methods provided on hand as public sector facilities ( $80 \%$ vs. $84 \%$ ).

Of the three countries, the highest percentage of faithbased facilities offering FP services is found in Haiti (89\%) (Table 4). Many faith-based facilities offer four or more modern methods (79\%), though only $39 \%$ offer any long acting method (compared to $50 \%$ of public and $29 \%$ of other private) $(p<0.05)$. The provision of long acting methods by health facilities in Haiti is low (21\%), though faith-based facilities are slightly more likely than other private facilities $(16 \%)$ to provide such methods $(p<0.05)$. In fact, for many of the availability indicators, faith-based facilities exhibit a pattern of higher coverage than other 
private facilities and lower coverage than public sector facilities. Routine user fees are common across all managing authorities (92-98\%) and most facilities offer FP services five or more days/week (92\%) $(p<0.05)$. Like Malawi and Kenya, stock is more likely to be on-hand for popular short-term methods, but IUCD was only on-hand for 55\% of facilities (though very few facilities offer this method to begin with $(n=31))$. Almost $60 \%$ of facilities had all methods provided available on the day of the interview.

\section{Comprehensive \& quality counseling}

Results for the nine indicators on comprehensive and quality counseling are shown in Table 5. Overall, there are fewer statistically significant differences by managing authority in these indicators than in the group of availability indicators. In Malawi, the percentage of providers in faithbased facilities writing on health cards and discussing a return visit is higher than the percentage of providers in public or other private facilities performing these skills $(p<0.05)$. However, providers in faith-based facilities do not perform as well on the other indicators, and are less likely to assure clients of confidentiality (15\% vs. $22 \%$ average) and discuss dual method use and STI/ HIV risk or prevention ( $8 \%$ vs. $18 \%$ average) $(p<0.05)$.

The selected counseling indicators do not significantly vary by managing authority in Kenya, with the exception of the provision of youth friendly-services. Though the indicator shows low coverage (27\%), providers in faithbased facilities and public facilities are more likely to provide such services ( $28 \%$ and $31 \%$, respectively) than are other private providers $(18 \%)(p<0.05)$.

Providers in faith-based facilities in Haiti are slightly more likely to write on client health cards (46\%) than are providers in facilities of other managing authorities (average 44\%), though the difference is non-significant, and are more likely to discuss a return visit $(79 \%)$ compared to public sector providers $(68 \%)(p<0.05)$. Other indicators with significant variation by managing authority include the discussion of dual method use and STI/ HIV risk or prevention, the provision of accurate information on use of the method, and the provision of youth friendly services. On the selected quality of counseling indicators, Haitian faith-based facilities often perform better than public facilities and the same as or lower than other private facilities. Four comprehensive and quality counseling indicators had an average coverage less than $20 \%$.

\section{Discussion}

This analysis compared the performance of faith-based facilities against public and other private facilities for a number of indicators on availability of FP services and quality of counseling. The analysis was conducted for three countries with recent SPA data. Results of this analysis show that FBOs manage between 13 and $20 \%$ of the health facilities in these countries; depending on the volume of clients in the facilities, these figures may or may not result in a provision of healthcare that is the "average of 40\%" often attributed to FBOs in subSaharan Africa and developing countries [1]. Faith-based facilities in these countries occupy a service provision space that is similar to the public sector: while the type of facility most commonly managed by FBOs varies by country (health centers in Malawi, dispensaries in Kenya, and clinics in Haiti), these are also the most common types of facilities for the public sector in each of these countries.

The availability of FP services by faith-based facilities varied by country. For example, the percent of faith-based facilities offering FP services in Malawi was 57\% compared to $89 \%$ in Haiti. However, faith-based facilities in the three countries generally lagged behind the other types of managing authority in indicators associated with FP service availability. This is especially true for the offer/provision of long acting methods. With the exception of Haiti, which actually performed better than public sector facilities on these indicators, faith-based facilities in Malawi and Kenya were much less likely to offer or provide long acting methods. Offering or providing at least four modern methods was also low for faith-based facilities in Kenya ( $44 \%$ and 39\% respectively). Upholding principles of volunteerism and the ability to freely choose methods requires that information about a range of methods is available. While not all facilities are equipped to provide long acting methods, all should be able to provide information and counseling on method options and referrals, especially if there are no religious restrictions to offering such methods. Improvements in service availability can be made in Malawi, Kenya and Haiti if more FBOs offer FP services, offer and provide a range of methods that includes long acting methods, and ensure method stock.

Comprehensive and quality counseling also varied by country, and by indicator, though there were fewer statistically significant differences between the managing authorities. This was especially the case in Kenya. Some indicators were relatively high for all managing authorities. For example, provider's discussion of client concerns/questions was fairly common in the three countries, with no statistical differences between managing authorities. Conversely, use of visual aids during counseling and provider's discussion of client's reproductive intentions was not common for any managing authority in any of the countries, and hardly occurred at all in Haitian facilities. There was also generally low coverage for assuring client confidentiality (22\% in Malawi, $47 \%$ in Kenya and 12\% in Haiti), and discussing dual method use and perceived risk of STI/HIV (18\%, $25 \%$, $17 \%$, respectively); these practices were particularly uncommon for FBOs in Malawi (15\% and 8\%, respectively). 


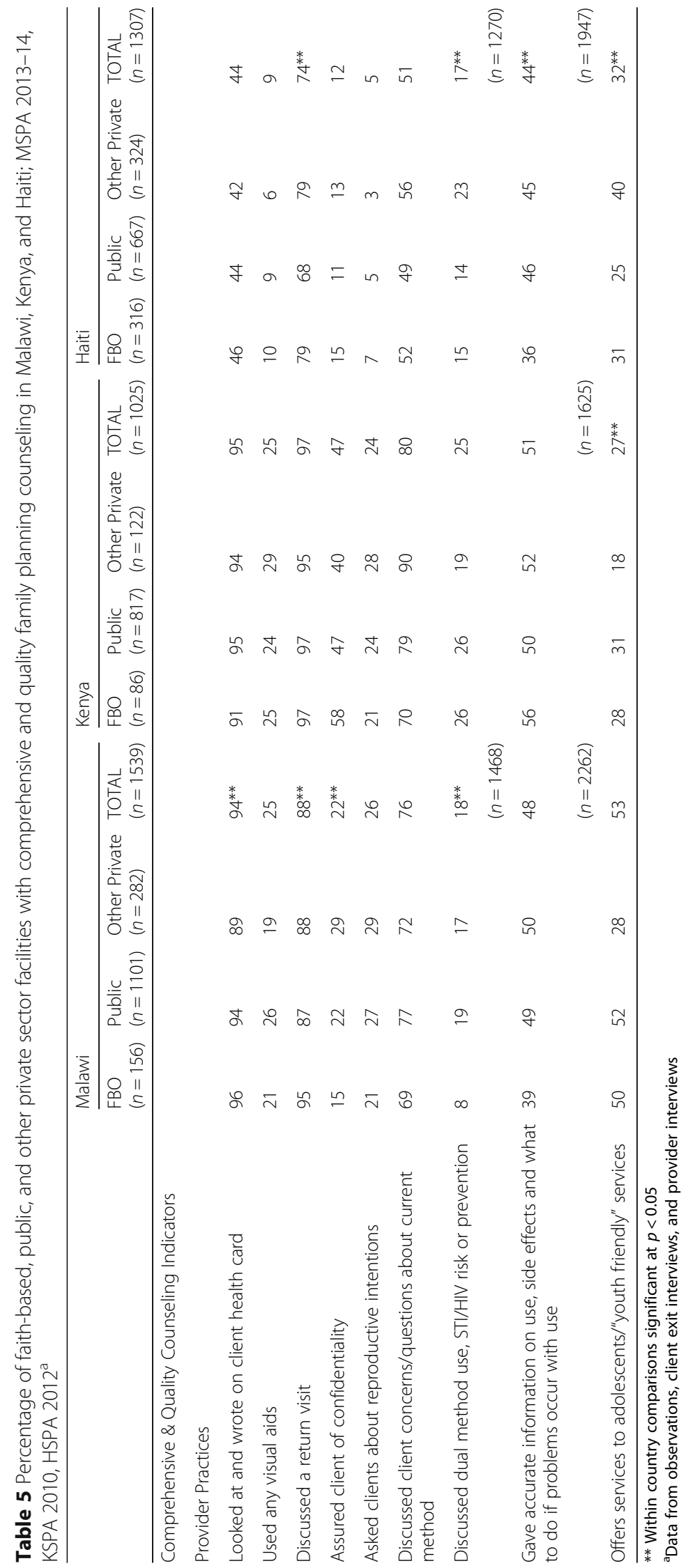


Approximately one-third of facilities in Kenya (27\%) and Haiti (32\%) and slightly more than half of facilities in Malawi (53\%) offer services to adolescents or "youth friendly" services, which suggests that the youth in these countries likely experience barriers to access FP services.

The percentage of providers in FBOs performing the assessed counseling indicators was often the lowest of the three managing authorities in Malawi; this was not the case in Kenya or Haiti. In fact, while the quality of counseling indicators show low coverage overall in Haiti, the performance of providers in faith-based facilities is generally better than the performance of providers in public sector facilities and sometimes better than that of the other private sector facilities. This may be due in part to intense work by FBOs to restore and improve the provision of health care after the earthquake in 2010 [26]. Because quality of care is key to the mission of serving communities and improving wellbeing, it is an area for potential strengthening among FBOs in Malawi.

The main strength of this analysis is that it uses recent, nationally representative data collected from health facilities. The data can be analyzed by managing authority, thus allowing for an analysis of services by the faithbased health sector. This analysis is therefore able to contribute information on a topic, the provision of health services by FBOs, which suffers from a lack of quantitative evidence. Moreover, the analysis is noteworthy in its focus on FBOs and FP services. This type of information is essential to inform faith networks, donor partners, policymakers, and other FP stakeholders, on potential service gaps and areas for future collaboration to strengthen the availability and provision of FP services to meet FP2020 goals. The analysis highlights two important elements of FP service delivery, the availability of services and methods and counseling, which may be of particular relevance for faith-based health care networks. The analysis also expands the evidence base by including a country from the Latin America and Caribbean region. A significant limitation of this analysis is that the specific religious affiliation of the FBOs is not collected in the SPA. As a result, information is lost by analyzing FBOs as one category, especially in countries such as Kenya, with many religions and denominations providing health care services, some with more restrictions than others. This is an important limitation as previous research has noted that heterogeneity among religious teachings can have fundamental effects on the provision of health care [17]. While the SPA is able to make comparisons across broad types of managing authorities, a modification to the SPA data collection tools to allow categorization of faith-based facilities by religion and denomination would greatly enhance research on this topic. In addition, facility-based surveys developed with the specific intent to assess variation in faith-based care are needed. Information derived from such surveys would be of great benefit to other service sectors looking to improve health market efficiencies and fill gaps where needed. Additionally, there are other aspects of FP service provision that were beyond the scope of the study. These include facility readiness and provider technical competency, as well as other indicators for service quality, such as treating the client with respect and having acceptable waiting times. It is not known how FBOs would perform on these other indicators.

\section{Conclusions}

FBOs have the potential to be important contributors to successful FP efforts. Identified facilitators for strengthening partnerships between faith-based and secular FP programs include emphasizing mutual goals, respecting philosophical differences, and including the faith community in the development of national FP strategies [9]. A diversity of partnership approaches may be necessary [8]. However, national FP programs need to ensure that volunteerism and free choice are upheld, which means ensuring access to information on a wide range of methods and maintaining choice for a wide range of methods, regardless of the service provider. Additional research is needed to better understand the role of FBO's in the provision of FP services in developing countries, especially by religion and denomination. Results from this analysis indicate that there is room for improvement in the availability of FP services by FBOs in these countries. Quality of counseling, especially with practices such as assuring client confidentiality, asking clients about their reproductive intentions, and discussing dual method use and STI/HIV risk or prevention should be improved by all managing authorities in the three countries, and particularly by FBOs in Malawi.

\section{Abbreviations \\ FBOs: Faith-based organizations; FP: Family planning; IUCD: Intrauterine contraceptive device; SPA: Service provision assessment; STI/HIV: Sexually transmitted infections/human immunodeficiency virus; USAID: United States Agency for International Development}

\begin{abstract}
Acknowledgements
Financial support for this work is provided by the U.S. Agency for International Development (USAID) under terms of Cooperative Agreement AID-OAA-L-1400004 and implemented by the Carolina Population Center, University of North Carolina at Chapel Hill in partnership with ICF International, John Snow, Inc., Management Sciences for Health, Palladium, and Tulane University. The views expressed in this article do not necessarily reflect the views of USAID or the United States government. The author is grateful to the Carolina Population Center and its NIH Center grant (P2C HD050924) for general support.
\end{abstract}

\section{Funding}

Financial support for this work is provided by the U.S. Agency for International Development (USAID) under terms of Cooperative Agreement AID-OAA-L-14-00004. The Carolina Population Center and its NIH Center grant (P2C HD050924) provides general support. 


\section{Availability of data and materials}

The datasets used during the current study are publically available from the DHS Program at http://dhsprogram.com/ [18-20].

\section{Authors' contributions}

The manuscript is the product of a single author.

\section{Competing interests}

The author declares that there are no competing interests.

\section{Consent for publication}

Not applicable.

\section{Ethics approval and consent to participate}

Consent and ethics approval were obtained by ICF Macro (the DHS Program) prior to data collection.

\section{Publisher's Note}

Springer Nature remains neutral with regard to jurisdictional claims in published maps and institutional affiliations.

Received: 28 October 2016 Accepted: 21 April 2017 Published online: 08 May 2017

\section{References}

1. Bandy G, Crouch A, Haenni C, Holley P, Larsen CJ, et al. Building from common foundations: The World Health Organization and faith-based organizations in primary healthcare. Geneva, Switzerland: World Health Organization; 2008. http://apps.who.int/iris/bitstream/10665/43884/1/ 9789241596626_eng.pdf. Accessed 10 February 2016.

2. African Religious Health Assets Programme. Appreciating assets: The contribution of religion to universal access in Africa. Cape Town, South Africa: World Health Organization; 2006. https://s3.amazonaws.com/berkleycenter/061000ARHAPAppreciatingAssets.pdf. Accessed 10 Feb 2016.

3. Kaiso G, Ragab ARA. Leap of faith: why religious leaders have a moral duty to promote family planning. The Guardian. 15 Oct 2015. http://www. theguardian.com/global-development/2015/oct/15/family-planningreligious-leaders-leap-of-faith. Accessed 11 Feb 2016.

4. Lavy V. Faith-based organizations and global health. Triple Helix. 2013:16-17. http://admin.cmf.org.uk/pdf/helix/spr13/th56p17-18.pdf. Accessed 11 Feb 2016

5. Kagawa RC, Anglemyer A, Montagu D. The scale of faith based organization participation in health service delivery in developing countries: Systematic review and meta-analysis. PLOS ONE. 2012;7(11): e48457. doi:10.1371/journal.pone.0048457.

6. Olivier J, Tsimpo C, Gemignani R, Shojo M, Coulombe H, et al. Understanding the roles of faith-based health-care providers in Africa: review of the evidence with a focus on magnitude, reach, cost, and satisfaction. Lancet. 2015; 386(10005):1765-75. doi:10.1016/S0140-6736(15)60251-3.

7. Widmer M, Betran AP, Merialdi M, Requejo J, Karpf T. The role of faith-based organizations in maternal and newborn health care in Africa. Int J Gynaecol Obstet. 2011;114:218-22. doi:10.1016/j.ijgo.2011.03.015.

8. Barot S. A common cause: faith-based organizations and promoting access to family planning in the developing world. Guttmacher Policy Rev. 2013; 16(4):18-23. https://www.guttmacher.org/gpr/2013/12/common-cause-faithbased-organizations-and-promoting-access-family-planning-developing. Accessed 11 Feb 2016

9. Institute for Reproductive Health. Faith-based organizations as partners in family planning: Working together to improve family well-being. Washington, D.C.: Georgetown University; 2011. http://www.ccih.org/FBOs_ as_Partners_in_FP_Report.pdf. Accessed 11 Feb 2016.

10. Institute R. Open letter to religious leaders on family planning. Religious Institute: Westport, CT; 2012. http://www.religiousinstitute.org/wp-content/ uploads/2014/02/Open-Letter-on-Family-Planning-with-endorsers-2014.pdf. Accessed 10 Mar 2016

11. Richards E. The Catholic Church and reproductive health and rights in Timor-Leste: contestation, negotiation and cooperation. Cult Health Sex. 2015;17(3):343-58. doi:10.1080/13691058.2014.966255.

12. Kenya National Bureau of Statistics (KNBS) and ICF Macro. Kenya demographic and health survey 2014. Calverton, Maryland: KNBS and ICF Macro; 2015. http://dhsprogram.com/publications/publication-FR308-DHSFinal-Reports.cfm. Accessed 11 Jan 2016.
13. Casterline JB, Sathar ZA, ul Haque M. Obstacles to contraceptive use in Pakistan: a study in Punjab. Stud Fam Plann. 2001;32(2):95-110. http://www. popcouncil.org/uploads/pdfs/councilarticles/sfp/SFP322Casterline.pdf. Accessed 11 Feb 2016

14. FP2020 Rights and Empowerment Working Group. Family Planning 2020: Rights and empowerment principles for family planning. 2014. http://ec254-210-230-186.compute-1.amazonaws.com/wp-content/uploads/2014/12/ FP2020_Statement_of_Principles_FINAL.pdf. Accessed 10 Mar 2016.

15. USAID. Family planning and reproductive health. 2016. https://www.usaid. gov/what-we-do/global-health/family-planning. Accessed 9 Jan 2017.

16. USAID. Volunteerism and informed choice. 2013. https://www.usaid.gov/ what-we-do/global-health/family-planning/voluntarism-and-informedchoice. Accessed 10 Mar 2016.

17. Tomkins A, Duff J, Fitzgibbon A, Karam A, Mills EJ, et al. Controversies in faith and health care. Lancet. 2015:386(10005):1776-85. doi:10.1016/S01406736(15)60252-5.

18. Ministry of Health $(\mathrm{MoH})$ [Malawi] and ICF International. Malawi Service Provision Assessment (MSPA) 2013-14. Lilongwe, Malawi and Rockville, Maryland, USA: MoH and ICF International; 2014. http://dhsprogram.com/ pubs/pdf/SR217/SR217.pdf. Accessed 5 Jan 2016.

19. National Coordinating Agency for Population and Development (NCAPD) [Kenya], Ministry of Medical Services (MOMS) [Kenya], Ministry of Public Health and Sanitation (MOPHS) [Kenya], Kenya National Bureau of Statistics (KNBS) [Kenya], ICF Macro. Kenya Service Provision Assessment Survey 2010. Nairobi, Kenya: NCAPD, MOMS, MOPHS, KNBS, and ICF Macro; 2011. http:// dhsprogram.com/pubs/pdf/SPA17/SPA17.pdf. Accessed 5 Jan 2016.

20. Institut Haïtien de I'Enfance (IHE), ICF International. Évaluation de Prestation des Services de Soins de Santé, Haïti, 2013. Rockville, Maryland, USA: IHE and ICF International; 2014. http://dhsprogram.com/pubs/pdf/SR211/SR211. pdf. Accessed 5 Jan 2016.

21. SPA Overview. http://dhsprogram.com/What-We-Do/Survey-Types/SPA.cfm. Accessed 10 Mar 2016.

22. Evaluation M. Quick investigation of quality $(\mathrm{Q} \mid \mathrm{Q})$ : A user's guide to monitoring quality of care in family planning ( $2^{\text {nd }}$ edition). Chapel Hill, NC: MEASURE Evaluation, University of North Carolina; 2016. https://www.measureevaluation. org/resources/publications/ms-01-02. Accessed 9 Jan 2017.

23. Westoff CF, Bietsch K. Religion and reproductive behavior in Sub-Saharan Africa. DHS analytical studies No. 48. Rockville, Maryland, USA: ICF International; 2015. http://dhsprogram.com/pubs/pdf/AS48/AS48.pdf. Accessed 11 Feb 2016

24. National Statistical Office (NSO) and ICF Macro. Malawi Demographic and Health Survey 2010. Zomba, Malawi and Calverton, Maryland, USA: NSO and ICF Macro; 2011. http://dhsprogram.com/pubs/pdf/FR247/FR247.pdf. Accessed 11 Jan 2016

25. Cayemittes $M$, Busangu MF, Bizimana JD, Barrère B, Sévère $B$, Cayemittes $V$, et al. Enquête Mortalité, Morbidité et Utilisation des Services, Haïti. 2012. Calverton, Maryland, USA: MSPP, IHE and ICF International; 2013. http:// dhsprogram.com/pubs/pdf/FR273/FR273.pdf. Accessed 11 Jan 2016.

26. Catholic Relief Services. Catholic Relief Services in Haiti: 5 Years after the earthquake. 2014. http://uspartners.crs.org/wp-content/uploads/2014/ 04/Catholic-Relief-Services-in-Haiti-5-Years-After-the-Earthquake.pdf. Accessed 9 Jan 2017 